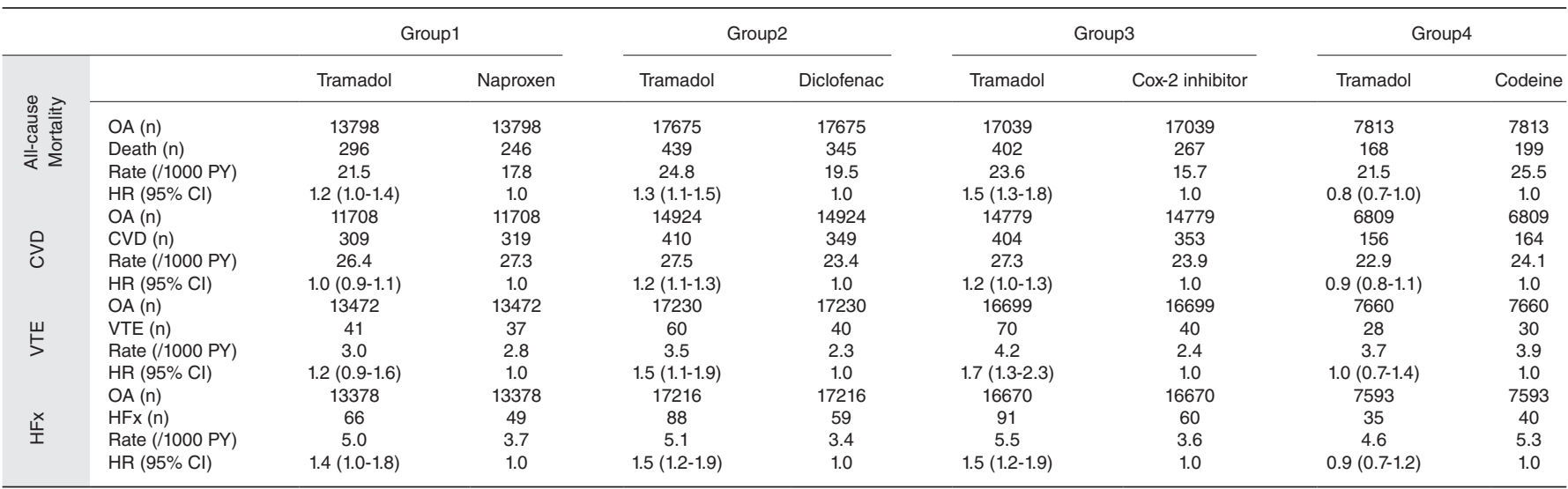
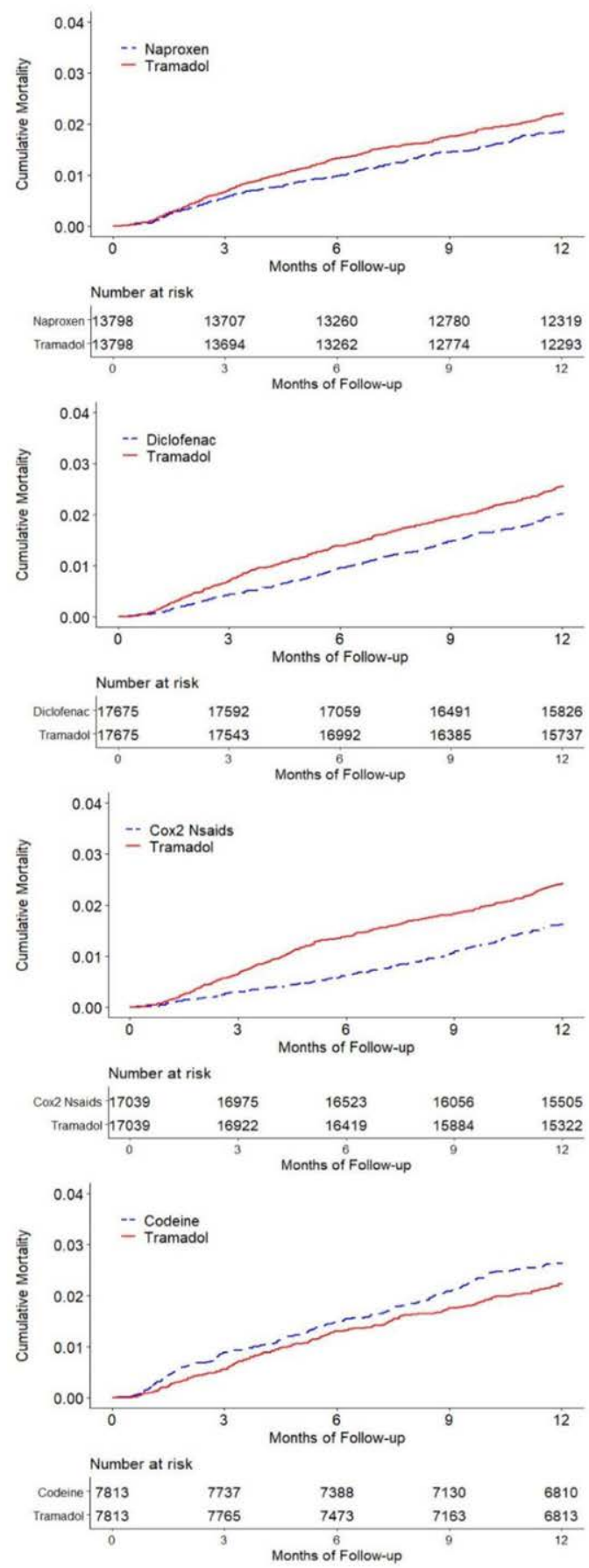

Disclosure of Interests: None declared DOI: 10.1136/annrheumdis-2020-eular.1889

\section{OP0192 PSORIATIC ARTHRITIS IS ASSOCIATED WITH A METABOLICALLY ADVERSE BODY COMPOSITION PROFILE PREDICTIVE OF GREATER CHD AND TYPE 2 DIABETES RISK - MRI FINDINGS FROM THE IMAPA AND UK BIOBANK STUDIES}

L. D. Ferguson ${ }^{1}$, J. Linge ${ }^{2}$, O. D. Leinhard ${ }^{2}$, I. Mcinnes ${ }^{3}$, S. Siebert ${ }^{3}$, N. Sattar ${ }^{1}$. ${ }^{1}$ University of Glasgow, Institute of Cardiovascular and Medical Sciences, Glasgow, United Kingdom; ${ }^{2}$ AMRA Medical AB, Linkoping, Sweden; ${ }^{3}$ University of Glasgow, Institute of Infection Immunity and Inflammation, Glasgow, United Kingdom

Background: Increased Body Mass Index (BMI) is associated with Psoriatic Arthritis (PsA) but with uncertain pathophysiological significance. BMI does not reflect body fat distribution, but fat storage site is important as increased ectopic fat including visceral adipose tissue (VAT), liver fat, and muscle fat infiltration (MFI), are associated with increased type 2 diabetes and coronary heart disease (CHD) risk ${ }^{1}$. To date no study has compared detailed body composition in PsA with the general population and other metabolic diseases.

Objectives: 1. To characterize the body composition profile of PsA compared to age, sex, and BMI-matched metabolic disease free (MDF) individuals, and type 2 diabetes. 2. To relate body composition to risk of type 2 diabetes and $\mathrm{CHD}$ in PsA versus MDF controls.

Methods: MRI body composition profiles were available for 29 PsA participants in the IMAPA study ${ }^{2}$. After excluding 3 participants with concomitant type 2 diabetes, body composition was compared in 26 PsA participants with 130 age, sex, and BMI-matched healthy MDF controls (matched 1:5) and 454 individuals with type 2 diabetes from UK Biobank, using Wilcoxon signed-rank test. Analyses were repeated adjusted for age, sex, and BMI. The propensity of PsA patients to develop CHD or type 2 diabetes based on their body composition profile was compared to that of matched MDF controls.

Results: PsA participants had significantly more ectopic fat including greater visceral adipose tissue (VAT) volume and liver fat percentage compared to MDF controls (table 1, figure 1A). This difference persisted after adjustment for age, sex, and BMI. Individuals with PsA shared a similar body composition to type 2 diabetes (table 1, figure 1B). Body composition-predicted propensity for $\mathrm{CHD}$ or type 2 diabetes was 1.3 and 1.8 times higher, respectively, for PsA compared to matched MDF controls.
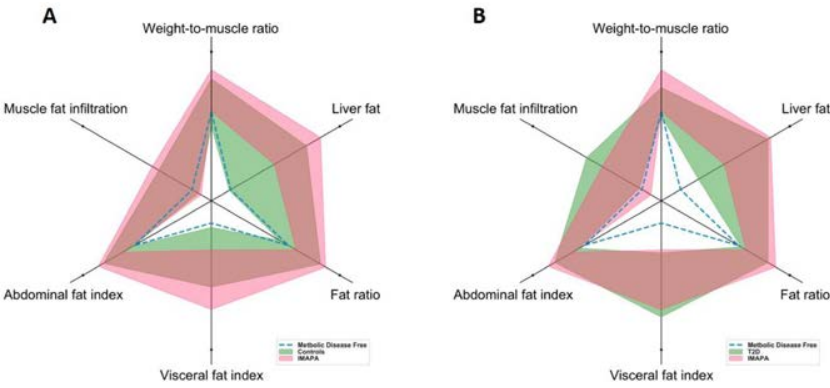

Figure 1. Body Composition Profiles of IMAPA PsA participants (pink) versus A. UK Biobank matched MDF controls (green), and B. type 2 diabetes (T2D) (green). 
Table 1. Comparison of body composition parameters in PsA, MDF controls, and type 2 diabetes

\begin{tabular}{|c|c|c|c|c|c|c|c|}
\hline Variable & PsA & MDF controls & $p$-value* & Adj. $p$ value ${ }^{\star \star}$ & Type 2 diabetes & $p$-value ${ }^{\dagger}$ & Adj. $p$ value ${ }^{\ddagger}$ \\
\hline Age (years) & $56.0(9.0)$ & $57.4(6.5)$ & 0.766 & - & $65.4(6.9)$ & $<0.001$ & - \\
\hline $\mathrm{BMI}\left(\mathrm{kg} / \mathrm{m}^{2}\right)$ & $31.2(6.4)$ & $30.5(5.3)$ & 0.799 & - & $29.9(5.2)$ & 0.397 & - \\
\hline VAT (L) & $5.89(2.10)$ & $4.34(1.83)$ & $<0.001$ & $<0.001$ & $5.93(2.56)$ & 0.662 & 0.301 \\
\hline Visceral fat index $\left(\mathrm{L} / \mathrm{m}^{2}\right)$ & $2.06(0.73)$ & $1.52(0.64)$ & $<0.001$ & $<0.001$ & $2.03(0.84)$ & 0.337 & 0.175 \\
\hline Abdominal subcutaneous adipose tissue $(\mathrm{L})$ & $10.48(4.90)$ & $9.42(4.86)$ & 0.288 & 0.071 & $8.58(3.93)$ & 0.109 & 0.339 \\
\hline Abdominal fat index $\left(\mathrm{L} / \mathrm{m}^{2}\right)$ & $5.87(2.39)$ & $4.93(2.29)$ & 0.084 & $<0.001$ & $5.04(1.92)$ & 0.052 & 0.024 \\
\hline Liver fat $(\%)$ & $8.88(4.42-13.18)$ & $3.29(1.98-7.25)$ & 0.002 & 0.002 & $6.13(2.77-11.63)$ & 0.392 & 0.656 \\
\hline MFI (\%) & $7.74(2.57)$ & $7.43(1.95)$ & 0.748 & 0.292 & $8.61(2.29)$ & 0.736 & 0.191 \\
\hline
\end{tabular}

Values are mean (SD) (liver fat, median (IQR)). ${ }^{*}$ PsA vs. MDF controls. **PsA vs. MDF controls adjusted for age, sex, and BMI. †PsA vs. Type 2 diabetes. $¥$ PsA vs. Type 2 diabetes adjusted for age, sex, and BMI.

Conclusion: This is the first study to report that individuals with PsA have a body composition profile associated with an adverse metabolic phenotype, with greater VAT and ectopic liver fat than the general population and more similar to that of type 2 diabetes, in line with their greater cardiometabolic risk. These data mandate a revision of the management approach to PsA that includes attention to weight loss interventions.

References:

[1] Linge et al. Body Composition Profiling in the UK Biobank Imaging Study. Obesity. 2018;26(11):1785

[2] Ferguson et al. Effect of PDE4 Inhibition with Apremilast on Cardiometabolic Outcomes in Psoriatic Arthritis - Initial Results from Immune Metabolic Associations in Psoriatic Arthritis (IMAPA) Study. Arthritis Rheumatol. 2019; 71 (suppl 10)

Acknowledgments: Celgene; $\mathrm{BHF}(\mathrm{RE} / 13 / 5 / 30177)$

Disclosure of Interests: Lyn D. Ferguson: None declared, Jennifer Linge Shareholder of: AMRA Medical AB, Employee of: AMRA Medical AB, Olof D. Leinhard Shareholder of: AMRA Medical AB, Employee of: AMRA Medical AB, lain Mclnnes Grant/research support from: Bristol-Myers Squibb, Celgene, El Lilly and Company, Janssen, and UCB, Consultant of: AbbVie, Bristol-Myers Squibb, Celgene, Eli Lilly and Company, Gilead, Janssen, Novartis, Pfizer, and UCB, Stefan Siebert Grant/research support from: BMS, Boehringer Ingelheim Celgene, GlaxoSmithKline, Janssen, Novartis, Pfizer, UCB, Consultant of: AbbVie, Boehringer Ingelheim, Janssen, Novartis, Pfizer, UCB, Speakers bureau AbbVie, Celgene, Janssen, Novartis, Naveed Sattar Grant/research suppor from: Boehringer Ingelheim, Consultant of: Amgen, Boehringer Ingelheim, AstraZeneca, Eli Lilly, Novo Nordisk, Sanofi, and Janssen, Speakers bureau: Amgen, Boehringer Ingelheim, AstraZeneca, Eli Lilly, Novo Nordisk, Sanofi, and Janssen DOI: 10.1136/annrheumdis-2020-eular.1074

\section{Dendritic cells as therapeutics}

\begin{tabular}{|l|l}
\hline OP0193 & BIIB059, A HUMANIZED MONOCLONAL ANTIBODY \\
TARGETING BDCA2 ON PLASMACYTOID DENDRITIC \\
CELLS (PDC), SHOWS DOSE-RELATED EFFICACY IN \\
THE PHASE 2 LILAC STUDY IN PATIENTS (PTS) WITH \\
ACTIVE CUTANEOUS LUPUS ERYTHEMATOSUS (CLE)
\end{tabular}

V. Werth ${ }^{1}$, R. Furie ${ }^{2}$, J. Romero-Diaz ${ }^{3}$, S. Navarra ${ }^{4}$, K. Kalunian ${ }^{5}$, R. Van Vollenhoven $^{6}$, F. Nyberg ${ }^{7}$, B. Kaffenberger ${ }^{8}$, S. Sheikh ${ }^{9}$, G. Radunovic $^{10}$, X. Huang ${ }^{11}, \mathrm{H}$. Carroll ${ }^{11}$, F. Gaudreault ${ }^{11}$, A. Meyers ${ }^{11}$, C. Barbey ${ }^{12}$, C. Musselli ${ }^{11}$, $\mathrm{N}$. Franchimont ${ }^{11}$ on behalf of the LILAC Investigators. ${ }^{1}$ University of
Pennsylvania, Philadelphia, United States of America; ${ }^{2}$ Northwell Health, Great Neck, United States of America; ${ }^{3}$ Instituto Nacional de Ciencias Medicas y Nutricion SZ, Mexico City, Mexico; ${ }^{4}$ University of Santo Tomas, Manila, Philippines; ${ }^{5}$ UCSD, La Jolla, United States of America; ${ }^{6}$ Amsterdam School of Medicine, Amsterdam, Netherlands; ${ }^{7}$ Karolinska University Hospital, Stockholm, Sweden; ${ }^{8}$ Ohio State University, Columbus, United States of America;

${ }^{9}$ University of North Carolina, Chapel Hill, United States of America; ${ }^{10}$ Institute of Rheumatology, Belgrade, Serbia; ${ }^{11}$ Biogen, Cambridge, MA, United States of America; ${ }^{12}$ Biogen, Baar, Switzerland

Background: CLE represents an unmet medical need with no approved therapy. BIIB059, a humanized monoclonal antibody, binds to BDCA2 and inhibits pro-inflammatory mediators production, including type I interferons. BIIB059 was evaluated in Phase 1 studies NCT02106897 and NCT03224793. LILAC is a 2-part Phase 2 study: Part A enrolled SLE pts; Part B enrolled pts with active CLE (NCT02847598)

Objectives: Evaluate efficacy and safety of BIIB059 in pts enrolled in Part B at Week 16, end of treatment (EOT) period.

Methods: Pts with active CLE, SCLE and/or CCLE and adjudicated Cutaneous Lupus Disease Area and Severity Index - Activity (CLASI-A) $\geq 8$ were enrolled and randomized to receive either BIIB059 $(50,150$ or $450 \mathrm{mg})$ or placebo (PBO) s.c. Q4W. Primary endpoint was dose response defined by \% change in CLASI-A score from baseline (BL) to Week 16. Secondary endpoints included CLASI-50 response rate and $\geq 7$-point reduction in CLASI-A score from baseline to EOT. Adverse events and serious adverse events were recorded throughout the study.

Results: 132 pts with active CLE were randomized. The study met its primary endpoint, demonstrating a dose response $(p=0.0005)$ and a statistically significant difference in \% change from BL in CLASI-A score in BIIB059-treated pts vs PBO. Table 1 and Table 2 summarize efficacy and safety results, respectively. Conclusion: BIIB059 administration to pts with active CLE resulted in statistically significant dose-related improvement in disease activity vs PBO with no untoward safety signals. Further development of BIIB059 in CLE is warranted.

Disclosure of Interests: Victoria Werth Grant/research support from: Biogen Celgene, Gilead, Janssen, Viela, Consultant of: Biogen, Gilead, Janssen, Abbvie, GSK, Resolve, AstraZeneca, Amgen, Eli Lilly, EMD Serono, BMS, Viela, Kyowa Kirin, Richard Furie Grant/research support from: AstraZeneca, Biogen, Consultant of: AstraZeneca, Biogen, Juanita Romero-Diaz Consultant of: Biogen, Sandra Navarra Speakers bureau: Astellas, Novartis, Pfizer, Johnson \& Johnson, Abbvie, Kenneth Kalunian Grant/research support from: Pfizer, Lupus Research

Table 1. Efficacy Endpoints

\begin{tabular}{|c|c|c|c|c|c|c|c|c|c|}
\hline \multirow[b]{2}{*}{ PBO } & \multicolumn{9}{|c|}{ BIIB059 } \\
\hline & \multicolumn{3}{|c|}{$50 \mathrm{mg}$} & \multicolumn{3}{|c|}{$150 \mathrm{mg}$} & \multicolumn{3}{|c|}{$450 \mathrm{mg}$} \\
\hline LS Mean (SE) & LS Mean (SE) & $\begin{array}{l}\text { LSMD }^{*} \\
\text { from PBO } \\
(95 \% \mathrm{Cl})\end{array}$ & $P$ val. & LS Mean(SE) & $\begin{array}{l}\text { LSMD }^{*} \\
\text { from PBO } \\
(95 \% \mathrm{CI})\end{array}$ & P val. & $\begin{array}{l}\text { LS Mean } \\
\text { (SE) }\end{array}$ & $\begin{array}{c}\text { LSMD }^{*} \\
\text { from PBO }(95 \% \mathrm{Cl})\end{array}$ & $P$ val \\
\hline
\end{tabular}

Primary Endpoint

CLASI-A \% change from BL

$-14.5(6.4) \quad-40.8(7.5) \quad-26.3(-45.7 ;-7.0) \quad 0.008 \quad-47.9(7.4)$

$-33.5(-52.7 ;-14.3) \quad 0.001 \quad-43.5(5.5)$

$-28.0(-44.5 ;-11.5) \quad 0.001$

Secondary Endpoints

\begin{tabular}{|c|c|c|c|c|c|c|c|c|c|c|}
\hline & $\mathrm{n}(\%)$ & $\mathrm{n}(\%)$ & $\begin{array}{c}\text { LSMD* }^{*} \\
\text { from PBO } \\
(95 \% \mathrm{Cl})\end{array}$ & P val. & $\mathrm{n}(\%)$ & $\begin{array}{c}\text { LSMD* }^{*} \\
\text { from PBO } \\
(95 \% \mathrm{Cl})\end{array}$ & P val. & $n(\%)$ & $\begin{array}{c}\text { LSMD* }^{*} \\
\text { from PBO } \\
(95 \% \mathrm{Cl})\end{array}$ & $P$ val. \\
\hline $\begin{array}{l}\text { Prop. of participants achieving } \\
\text { CLASI } 50\end{array}$ & $7 / 32$ (21.9\%) & $10 / 26(38.5 \%)$ & $15.8 \%(-7 ; 39)$ & 0.133 & $11 / 25(44.0 \%)$ & $21(-2.8 ; 45)$ & 0.059 & $20 / 43(46.5 \%)$ & $23(3 ; 44)$ & 0.024 \\
\hline $\begin{array}{l}\text { Prop. of participants achieving a } \geq 7 \text { - } \\
\text { point CLASI-A reduction from } B L\end{array}$ & $7 / 32(21.9 \%)$ & $9 / 26(34.6 \%)$ & $12.3(-11.3 ; 35.8)$ & 0.228 & $12 / 25(48.0 \%)$ & $22.2(-2.0 ; 46.3)$ & 0.055 & $18 / 43(41.8 \%)$ & $16.8(-6.7 ; 40.4)$ & 0.048 \\
\hline
\end{tabular}

*LSMD=LS Mean Difference 